\title{
The Phenomena of Interlanguage Interference at the Morphemic Level
}

\author{
Malahat Akbar Veliyeva ${ }^{1}$ \\ ${ }^{1}$ School of English, Azerbaijan University of Languages, Baku, Azerbaijan \\ Correspondence: Malahat Akbar Veliyeva, School of English, Azerbaijan University of Languages, Baku, \\ Azerbaijan. Tel: 994-055-704-2476. E-mail: malahatveliyeva@yahoo.com
}

$\begin{aligned} & \text { Received: January 22, } 2016 \\ & \text { Accepted: February 19, } 2016 \quad \text { Online Published: March 28, } 2016 \\ & \text { doi:10.5539/ijel.v6n2p124 }\end{aligned} \quad$ URL: http://dx.doi.org/10.5539/ijel.v6n2p124

\begin{abstract}
The phenomena of language interference at the morphemic level as a type of grammatical interference were not accepted by the linguists who considered morphological interference impossible. However, there are linguists who claim that in language contacts morphological systems of languages affect each other and they consider it quite acceptable.

Divergences in morphological systems of contacting languages cause morphological interference in bilinguals' speech. Morphological peculiarities of contacting languages explain the reason of such deviations. Morphemes are two-sided units which are identified by the unity of phonetic or exponential (expository) and semantic features. Due to major differences in morphological structures of English and Azerbaijani languages, Azerbaijani students confuse English morphemes with the morphemes in their native language that is reflected in the phenomena of morphemic interference in their speech. So, in the study of morphemic interference it is significant to consider the types of contacting languages that is the basis of typological research in condition of bilingualism and language contacts.
\end{abstract}

Keywords: exponential variation, interference, morpheme, morphemic level, semantic variation

\section{Introduction}

Out of wide range of the phenomena of interference at different levels of the language we will focus our attention on morphological interference which is a type of grammatical interference; we will investigate it as the interference at the morphemic level. The main objective of the study is to identify the reasons and the sources of morphological interference in bilinguals' speech.

From the history of linguistics it is known that grammatical, in particular morphological, interference was not accepted by linguists such as A. Meyer (Meyer, 1996), E. Sapir (Sapir, 1921), who considered morphological interaction of languages impossible.

Another group of linguists, such as U. Weinrich (Weinrich, 1979) and E. Haugen (Haugen, 1972) completely oppose to the above stated opinion and claim that in language contacts morphological systems of languages affect each other and they consider it quite acceptable.

\section{Literature Review}

The reasons and the sources of grammatical, particularly, morphological, interference in bilinguals' speech are divergences in morphological systems of contacting languages. To explain the reasons of such deviations it is necessary to apply to morphological peculiarities of contacting languages.

According to Kh. Z. Bagirokov who researched morphological interference in Adygeys' Russian speech "interference in second lingual speech can be determined, firstly, by the difference in the structure of the language, and secondly, by the complicated character of the interaction of the units of the mother tongue and the second language in speech" (Bagirokov, 2004).

The "morpheme" is the key notion in the research of the phenomena of interference. It is the unit of the morphological level of the language introduced into linguistics by Boduen-de-Kurtene and is understood as an inseparable, minimal and elementary unit of the language in the plan of expression and content (Boduen-de-Kurtene, 1963). For example, in English morphemes /map/, /bell/, /ship/, etc. are meaningful and possess a definite sense, at the same time each of them is not separated into minimal parts. 
As the Azerbaijani linguist F. Veysalli considers, morphemes of the language are two-sided units differing in independence; their amount in every language is limited and the most significant point in their identification is the unity of phonetic, otherwise called exponential (expository) and semantic features (Veysalli, 2007). Morphemes are subdivided into: root or free (e.g., /gap/, /fat/, /bat/) and affixational which are otherwise called grammatical morphemes.

To facilitate the study of morphemic interference E. Haugen suggested the term "diamorphs"-morphemes characteristic to different languages having constant and regular correspondences, and the relations between these morphemes_- "diamorphic" (Haugen, 1972). Such parallels can be drawn between languages having more or less similar grammatical categories and correspondent morphemes. It means that the character of morphemic interference in languages will be determined by the degree of kinship, similarities and differences in their morphological systems.

\section{Research Methodology}

Direct observation, comparative and linguistic description methods were used in this article. To register the cases of the phenomena of interference at the morphemic level we directly observed the oral and written English speech of Azerbaijani students whose second language is English. Comparative method is necessary to identify the reasons of morphemic interference determined by the peculiar structural features of contacting languages.

By the method of linguistic description we could research the language from the synchronic aspect and describe the phenomena of interference and the mistakes caused by interference in bilinguals' speech.

\section{The Phenomena of Interlanguage Interference at the Morphemic Level}

The ability to transfer the morphemes in bilinguals' speech also depends on the complexity of grammatical functions of morphemes. For example, in the speech of Azerbaijani students studying English the most frequent case of morphemic interference is the transfer of the word morpheme " $\mathrm{o}$ "- $\mathrm{a}$ pronoun in the third person singular deprived of the category of gender in Azerbaijani, into the morpheme "she"-a pronoun in the third person singular of feminine gender in English. The transfer of the morphemes participating in the formation of Passive Voice in Azerbaijani in studying the corresponding forms in English is the least likely as these morphemes have got not simple but complicated functions. Very frequently, the target language that is the second language has a direct influence on the bilingual's mother tongue. In such cases the phenomena of the interference of free word-morphemes occur from English (in cases with Azerbaijani-speaking students) into Azerbaijani. Such cases of interference observed in the situations when there are necessary linguistic and extra linguistic causes are manifested in languages, are reflected in borrowings. In such conditions word-morphemes transferred into the language are either included in vocabulary stock of the language and receive the citizenship in the language or fail to coexist with native words and become exotic words or realia expressing the peculiar cultural features of the people whose language is learnt.

However, the cases of interference should not be confused with borrowings. The phenomena of interference are more likely to be deviations from the norms which should be revealed as a result of investigation; due to this fact special methods of their correction in bilingual individuals' speech should be worked out and implemented. Thus, the consequences of language contacts can be reflected both in borrowings which lead to replenishment of vocabulary stock of the language and in phenomena of interference which must be prevented by methodologists for more successful mastering of the foreign language.

U. Weinrich admits the significant role of transferring of morphemes from one language into the other in the study of interference considering that even monolingual individual can split the root and affixational morpheme in double morpheme unit and use the corresponding affix with others as wells as native roots (Weinrich, 1979). It means that, morphological system of the language is available and admits transfer of morphemes not only in conditions of bilingualism, but also in case of monolingualism. Talking about morphemic interference, U. Weinrich differentiates the cases where transfer of morphemes takes place (he speaks about "language- donor" and "language-recipient"), and the cases where none of the morphemes are transferred and distinguishes "model-language" and copying language ("the replica language) (Weinrich, 1979). The condition of bilingualism in direct contact of languages or while studying the second language can be related to the first case.

In comparative-typological research of contacting languages it would be preferable to use the morphonological theory suggested by N. S. Trubetskoy which implies the phonological structure of morphemes, combinatory sound changes of morphemes in morphemic combinations, sound variations, carrying out morphological function (Trubetskoy, 1967). As well as in the process of borrowing where the donor language strongly affects the phonetic, morphological and lexical system of the language in conditions of bilingualism while mastering the 
second language the phenomenon of morphological variability, the influence of morphemes of contacting languages to each other are observed.

A. V. Ageyeva, investigating morphological variability of the French lexis in modern Russian, determines it by strong influence of Russian morphemes («контрафакт (counterfeiting)—контрафакция», «пролонгация (prolongation, renewal)-пролонгирование», etc.) that affectsthe peculiarities of functioning and semantics of foreign language lexeme (Ageyeva, 2011).

The real example of the ability of mutual interference at morphemic level of the language is I. S. Kazimirova's research dedicated to the morpheme interference in verb forms of French and Russian languages taking into consideration the cases of interlanguage and intralingual contacts (Kazimirova, 1984). In the study of morphemic interference it is also necessary to consider the language type that is the basis of typological research in conditions of bilingualism and language contacts. Analytical type of the English language and tendency to agglutination and root isolation is especially manifested in paradigmatic relations of analytical verb lexemes of English (Borodina, 2004).

In contacting of two languages of the same type, particularly, Azerbaijani and English both of which are analytical and tend to agglutination, the phenomena of interference at morphemic level are more likely. Bilingualism can also cause the formation of mixed languages as a result of interpenetration of two morphological systems, for example Lezgin, Talish languages which are spoken by ethnic minorities living on the territory of Azerbaijan and closely contact with Azerbaijani language the elements of which are directly reflected in their language systems. Such active interaction of languages is expressed in borrowings which are assimilated in the language and receive complete citizenship.

In the study of interference at morphemic level comparative-historical and typological methods are very helpful as the language theory is directly connected with Comparative Linguistics. To reveal the phenomena of morphemic interference in the speech of Azerbaijani students speaking English, the comparison of morphemes in two languages and their functions to justify the reasons leading to interpenetration of morphemes is unavoidable. For example, the phenomenon of interference took place in the process of historical interaction of both related and unrelated languages. As, for example, English, being one of Germanic languages, in the process of historical development acquired some elements alien to Germanic languages like Latin element preserved in endings of some geographical names-Manchester, Winchester, Colchester, etc. Also, such morphemes (prefixes and suffixes) as:

« inter- international

super- superhuman

- ist $\quad$ socialist, capitalist

-ism socialism, capitalism» were borrowed from Latin (Hajiyeva, 2011).

While investigating language phenomena it is important to take into consideration the fact that the units of all levels of the language are interelated and regarded not in isolation from each other but as an integral whole. The elements of all language levels carry out their function in the process of communication, "between the elements of the language at all its levels there is interdependence of such kind that the language can not possess one of the elements without the other" (Islamova, 2010).

As per J. L. Austin, the language units of all language levels in total play an essential role in the process of comminucation and each unit, in its turn, is an important component in the realisation of speech, in other words in "speech act" (Austin, 1962).

The problem of linguists studying the issue of bilingualism is to reveal distinctive features of contacting language systems which cause challenges in mastering the second language, also to some extent to prevent possible manifestations of interference taking place in language contacts. At the same time there are such cases of mastering a foreign language when bilingual individuals easily learn the second language at the same level as their mother tongue when the phenomenon of interference can be manifested very slightly. For other group of learners the study of the second language is much more difficult, it costs them enormous efforts that are explained by psychological and individual characteristics of bilingual individuals, by inborn abilities to master a foreign language. In such cases the phenomenon of interference is unavoidable and determined by bilinguals' speech behavior, degree of kinship of contacting languages and the dominating language, the language in which the individual "thinks".

At morphological level the real consequence of interference can be the borrowing of word forming morphemes 
of French origin by English as in the example of productive diminutive suffix «-ette» in the following words: "kitchenette, roomette, cigarette, statuette" and others given by U. Weinreich [www.philology.ru/linguistics 1/weinreich -72.htm]. This example of the borrowing of the word forming morpheme is the evidence of significant influence of one language to the other and the result of the phenomenon of interference in the speech of bilinguals mastering English and French.

Thus, interference at morphemic level causes difficulties arising in studying a foreign language and at the same time can affect morphological system of the language.

While studying morphemic interference it is important to focus on interference determined by exponential and semantic variation of morphemes. As it is known, morpheme is one of the essential units of the language structure and is defined as minimal inseparable into simpler units with similar feature and possessing a definite exponent (phonetic form, the form of expression) and content, semantic side. In other words, a morpheme has the plan of expression and the plan of content. In functioning of the morpheme we observe the variation of their sound form depending on their positions and determined grammatically (in this case the morpheme functions as grammatical and morphological variant) and phonetically (in such cases the morpheme functions as phonetic variant). For example, in Azerbaijani "getmək" (to go), "gedir" (is going) - the root morpheme is in grammatical position ("getmək"-infinitive form of the verb and "gedir"- the form of Present Tense form). A similar example can be given in English, "man" (singular noun) and "men" (plural noun). Such alternation of variants is determined by grammatical position: singular form of the noun "man" and plural form "men", which is not formed by general rule of forming plural nouns in English. The examples of variants determined by phonetic position of morphemes in Azerbaijani can be the following morphemes: "gəl" (the verb "to come" in Imperative Mood "come") and "göl" (a noun with the meaning "lake").

The principle of dismemberment of the word forms into constituent parts which are carriers of lexical (real) and grammatical meanings is observed in majority of world languages. For example,

1) The nouns in Azerbaijani in Nominative Case - "təbiət" (nature) - the root morpheme in Possesive Case "təbiat—in" (of nature) — root morpheme + grammatical morpheme of Possessive case - "-in". In the English language the noun in Nominative Case "sister" (root morpheme) and "sister-'s" consists of the root morpheme + grammatical morpheme of Possessive Case "-'s".

2) Adjectives: in Azerbaijani language "sir-li" (mysterious) consists of the root morpheme "sir" (mystery) + grammatical morpheme forming adjectives "-li". In English «comfort-able»- the root morpheme «comfort»+ grammatical morpheme «-able» serving for forming adjectives in English.

3) The verb in Azerbaijani «su-la-maq» (to water), in English «just-ify».

The same grammatical morpheme of Possessive Case in Azerbaijani language is amenable to variationin the example: "səmanın" turning into "-1n" and undergoing phonetic change of the phoneme [i] into [1] under the influence of the previous vowel [a]according to the law of vowel harmony in the grammar of the Azerbaijani language.The similar variation of morphemes is observed in the English form of the adjective in the example - "comfort-able"- "respons-ible", where the morpheme "-able" alternates with the form "-ible".

Thus, in Linguistics a morpheme is a set of language varaints-allomophs. The amount of allomorphs is determined by grammatical and phonetic reasons. Approaches to the issue of morpheme variations in Linguistics are ambiguous. According to Y. S. Maslov, for example, any material variation, external, exponential expression of the morpheme with similar meaning should be considered as the variants of one and the same morpheme (Maslov, 1961). It follows from this point of view that by the example of English it is necessary to identify morphemes- "grate-ful, vis-ible, confid-ent", forming adjectives as variants of one and the same morpheme with different exponential expression but similar semantic form. In contrast to this opinion in Linguistics variation, homonymy, homosemy and polysemy of morphemes is distinguished. The above-mentioned cases with common meaning but different sound form are related to homosemy. As, for example, in Azerbaijani language the morphemes of Accusative Case (təsirlikhal) - "açarı"-the key, "gəmini"- the ship, "güzgü-n-ü" - the mirror, "moruğu"- the raspberry. Homonymous morphemes are those which have analogical material form but absolutely different meanings. As, for example in Azerbaijani language the morpheme "-lar" having the grammatical meaning of plurality of nouns in cases: "tarla-lar" (fields), "qatar-lar" (trains), "çanta-lar" (bags) etc. and denoting the meaning of Future Tense Form in cases: "çağ-lar" (will burble), "ağ-lar" (will cry), "siz-lar" (will whine), etc. In English the homonymous morpheme can be the morpheme "-ing" serving to form Participle I or present participle (He is swimming in the river.), at the same time serving to form Gerund (Reading is my favourite hobby.). 
Linguists talk about polysemy when morphemes can have several semantically connected with each other meanings. As, for the example, the morpheme "-ed" in English has the meaning of the Past Tense of regular verbs (visit-ed, want-ed, answer-ed, etc.), also participates in forming of participle II, past participle of regular verbs (require-ed field, complet-ed task, desir-ed month, etc.)

In Azerbaijani the morpheme "-l1" which has the grammatical meaning of the adjective, like "qar-l1"-snowy, "vüqar-l1"-proud, "şaxta-lı"-frosty, "yağış-l1"- rainy) can also occur in the words denoting origin ("Qarabağ-lı"-from Karabakh , "Şuşa-lı"-from Shusha, "Bakı-lı"-from Baku , "Amsterdam-lı"—from Amsterdam).

The variation of morphemes is determined by the following reasons:

1) phonetic, due to lively phonetic processes, for instance, in Azerbaijani language "kal"[ "kæl]—unripe, "fal" ['f $\Lambda \mathrm{l}]$ - fortune telling; in English the suffix of plurality in words "maps"- $[\mathrm{s}]$, "bags"- $[\mathrm{z}]$;

2) historical, that is variation of morphemes as a result of phonetic processes in diachronic plan at some definite stage of the development of the language. For example, in Azerbaijani-“nəsr"-prose, " nasir"-prosaist, in English "goose"(singular) — "geese" (plural);

3) morphological, that is grammatically determined variations. For example, in Azerbaijani the morphemes of Future Tense Form "gəl+ ər"-will probably come, "gələ+cək"-will come, in English the morphemes of the Past tense of irregular verbs: "broke" (past tense form of the verb), "broken" (the form of Past participle).

As to the correlation of a word and a morpheme, the morpheme is a part of the word, in case of the root morpheme it can coincide with the word form. Also, in comparison with the word, the morpheme is the smallest sign unit of the language deprived of lexical-semantic interrelationship. "A morpheme as well as a word has different functions (nominative, significative, communicative (flexions), pragmatic), but carries them out indirectly in the structure of the word." (Nikolina \& Ratsiburskaya, 2013). Roots in the structure of notional words are carriers of lexical meanings usually similar to the lexical meaning of words which are simpler according to the morphological structure and comprise these roots.

As to B. A. Serebrennikov while defining the notion of morpheme it is necessary to consider its relation to a more complex higher unit in the language structure, specifically the fact whether the morpheme is regarded as a constituent part of a word, lexical unit or the sentence, the syntactical unit (Serebrennikov, 1972). Affixes do not possess an independent lexical meaning, they have either lexical-grammatical (word forming, derivative) or purely grammatical, expressing relationships, or they carry out formal-structural and formal-classifying functions. Morphemes are the basis, presupposition, means of forming more complex units of the language - $\mathrm{a}$ word. Depending on the grammatical structure of each word of a similar type, this basis can be used differently.

In linguistic literature the source of variability of root morphemes is "usage of one morpheme in several material variations", also "change in morphemic sphere of the language", that is merging of some suffixes with the root into one morpheme as a result of change and loss of the meaning of suffixes (Timofeyev, 1986).

So, in Morphology free (root) and word building morphemes are distinguished. In English Linguistics free morphemes are subdivided into lexical (those which coincide with word forms and carry some semantic load) and functional (functional words having grammatical functions, as, for example, prepositions "for", "on", conjunction "but", relative pronoun ,etc. (Kenworthy, 1994). Consequently, functional words are morphemes and should be considered in the study of interference at morphemic level.

Azerbaijani linguist F. Y. Veysalli gave a detailed description of the typology of morphemes explaining their exponential differences:

1) difference in components;

2) structuraldifferenceorpalindrome;

3) continuative and discontinuative (Veysalli, 2011).

By the example of English, German and Azerbaijani languages F. Y. Veysalli gave the analysis on distinguishing the exponents of morphemes in the above-mentioned languages (Veysalli, 2013).

Considering exponential and semantic description of morphemes it is possible to review the phenomenon of interference determined by exponential variation of morphemes in conditions of Azerbaiani-English bilingualism. Such type of interference is observed in the speech of Azerbaijani students learning English. The most frequent mistakes made by the students occur in such variants of morphemes determined by their exponential variation, as in the words: "caps", "songs" [z], "matches" [1z] which are pronounced by students as 
[s] - is one of the variants of this morpheme. Variation in the pronunciation of the shown morpheme is determined by the previous consonant:

1) after the unvoiced consonant is pronounced as [s];

2) after voiced consonant as [z];

3) after sibilant sounds as [1z] that is often ignored by the students especially at earlier stages of learning the language.

Such kind of interference is observed in the pronunciation of the verb morpheme of Past tense "-ed". Most frequently students pronounce this morpheme as [1d] in all variants as, for example:

1) [1d] instead of [d] in such words as "said";

2) [1d] instead of [t] in the case with verbs "asked", "finished"“liked", "looked", "watched", "worked" etc.

3) [1d] instead of [d] in the example "changed", "listened".

\section{Conclusion}

The phenomena of morphemic interference unavoidably occur in bilinguals' speech in conditions of bilingualism as morphological structures of contacting languages interact and affect each other, especially if the languages belong to different types.

The study of exponential and semantic features of morphemes characteristic to contacting languages, promotes to better understanding of interference phenomena in bilinguals' speech. The investigation of the reasons of morphemic interference in the speech of Azerbaijani students learning English is revealed by comparison of morphemes in two languages. Exponential and semantic description of morphemes should be considered for the investigation of interference phenomenon determined by exponential variation of morphemes in conditions of Azerbaijani-English bilingualism.

\section{References}

Ageyeva, A. B. (2011). Variability as a universal regularity of mastering foreign language vocabulary (p. 21). Nizhniy Novgorod.

Austin, J. L. (1962). How to do things with words. Oxford: Clarendon Press.

Bagirokov, Kh. Z. (2014). Bilingualism: theoretical and applied aspects (on the material of Adigey and Russian languages) (p. 62). Adiyey State University, Maykop.

Baudouin de Courtenay, I. A. (1963). Selected works on General Linguistics, I, 65-66. Moscow.

Borodina, T. L. (2004). The features of paradigmatic relations of analytical verb lexemes in Modern English (with "get" and "make" as verb components)—Actual problems of Modern German Studies (pp. 7-14.). Novosibirsk.

Hajiyeva, A. (2011). English Lexicology. Science and Education (p. 94), Baku.

Haugen, E. (1972). Language Contact /New in linguistics (pp. 61-80). Moscow.

Islamova, E. S. (2010). The aspects of linguisticrealia (p. 101). Baku, Mutarjim.

Kazimirova, I. S. (1984). Prevention of difficulties as one of the ways of intensification of mastering the grammatical material by the student. Intensification of teaching receptive and productive types of speech activity. Moscow, MSPU.

Kenworthy, J. (1994). Language in Action. An Introduction to Modern Linguistics (p. 29). London, New York: Longman.

Maslov, Y. S. (1961). About some divergences in understanding of the term "morpheme". Scientific Notes LSU, № 301, Series of Philological sciences, 60, 140-152.

Meyer, A. S. (1996). Lexical access in phrase and sentence production: results from picture-word interference experiments. Journal of Memory and Language, 35(4). http://dx.doi.org/10.1006/jmla.1996.0026

Nikolina, N. A., \& Ratsiburskaya, L. V. (2013). Modern Russian. Morphemics: teaching aid. Moscow, "Science”, p.16.

Sapir, E. (1921). Language: An introduction to the study of speech. New York: Harcourt, Brace and company.

Serebrennikov, B. A. (1972). General Linguistics: inner structure of the language. Moscow, "Science”, p. 235. 
Timofeyev, K. A. (1986). Variability in word formation. Variable relations in lexis (pp. 3-13). Novosibirsk.

Trubetskoy, N. S. (1967). Some considerations concerning Morphonology (pp. 115-119). Moscow.

Veysalli, F. Y. (2007). Language. Education, p.188

Veysalli, F. Y. (2011). Elements of General and Special Linguistics. I part, Baku, “Mutarjim”, pp. 282-283.

Veysalli, F. Y. (2013). Exponential and semantic description of morphemes. Turkology, Azerbaijan National Academy of Sciences, Institute of Linguistics named after Nasimi.

Weinreich, U. (1979). Languages in Contact. Kiev, Vishashkola, p. 63. http://dx.doi.org/10.1515/9783110802177

Zhluktenko, Y. A. (1974). Linguistic aspects of bilingualism. Kiev, Vishashkola, p.101.

\section{Copyrights}

Copyright for this article is retained by the author(s), with first publication rights granted to the journal.

This is an open-access article distributed under the terms and conditions of the Creative Commons Attribution license (http://creativecommons.org/licenses/by/3.0/). 